\title{
United States Innovations in Healthcare Delivery
}

\author{
Stephen M. Shortell, PhD, M.B.A., M.P.H, ${ }^{1}$ \\ Robin Gillies, $\mathrm{PhD},{ }^{2}$ \\ Frances $\mathrm{Wu}, \mathrm{BS}, \mathrm{MS}^{3}$
}

\begin{abstract}
Population aging, rapidly increasing costs of healthcare and the growing burden of chronic disease are challenges to health systems worldwide. To meet these challenges will require new approaches to healthcare delivery and comprehensive population health management. Within the context of healthcare reform initiatives, important innovations in delivery system organization in the United States are discussed. The innovations focused on are the Patient-Centered Medical Home (PCMH), the Accountable Care Organization (ACO) and the Population Health Management System (PHMS) combined with new payment arrangements that reward for health outcomes achieved rather than paying a fee for each service rendered. For each of these innovations, the evidence on its performance, the challenges involved, and the factors that might promote greater adoption and diffusion of successful models are reviewed. Finally, the role played by a country's political system and its associated culture, structural barriers, size and resources, incentive alignment, and leadership are discussed.
\end{abstract}

Keywords: United States health reform, Patient-Centered Medical Home, Accountable Care Organization, Population Health Management System

\section{INTRODUCTION}

Nearly all nations are working to improve their healthcare delivery systems. The growth of chronic illness and aging populations, in particular, has placed a substantial burden on healthcare systems in both developed and developing countries. For example, 60 percent of all deaths worldwide (25 million people) are due to chronic illness. Eighty percent of these occur

\footnotetext{
${ }^{1}$ Blue Cross of California Distinguished Professor of Health Policy and Management, and Dean, School of Public Health, University of California, Berkeley.

${ }^{2}$ Researcher, School of Public Health, UC-Berkeley.

${ }^{3}$ Ph.D. Student, School of Public Health, UC-Berkeley.
}

Correspondence: Stephen Shortell at email shortell@ berkeley.edu 
in low and middle-income countries, and deaths due to chronic illness are double the number due to infectious diseases. ${ }^{1}$ Chronic illnesses also have a huge economic impact. For example, over the next ten years, chronic illness will result in $\$ 558$ billion of costs as well as lost productivity in China; $\$ 237$ billion in India; and $\$ 33$ billion in the United Kingdom..$^{2}$ In the US, nearly three-quarters of Americans over the age of 65 suffer from a chronic illness ${ }^{3}$ and half of them have more than one chronic illness. Chronic illness in the United States accounts for 75 percent of the \$2.4 trillion of healthcare expeditures. ${ }^{4}$

At the same time, there is growing recognition that a country's health status is heavily influenced by underlying economic, physical, environmental, and social determinants. These involve multiple sectors outside of healthcare including agriculture, education, housing, and transportation among others. Savings that might accrue from having more cost-effective healthcare delivery systems to treat chronic illness could be redeployed in health promotion and related activities offering a greater return on investment in improving population health. As a result, there is growing interest in both the primary prevention of chronic illness and in better management of those with existing chronic illness.

The US has the most expensive healthcare system in the world (16 percent of GDP) with health status indicators that are, at best, only average in comparison with the less costly health systems of other countries. Thus, the pressure to provide more cost-effective care is particularly intense in the US, as it attempts to expand health insurance coverage and address serious cost and quality issues. Earlier efforts to expand the health maintenance organizations (HMOs) established in the 1970s to reduce costs backfired when both physicians and patients rebelled against the limited choices and prior authorization required for certain services and referrals to specialists. The result has been a relative decline in group practice HMOs and a relative increase in preferred provider organizations (PPOs) whose attempts to exercise cost containment and quality improvement initiatives are generally less systematic than those undertaken by HMOs. The result is that providers in the US remain largely fragmented, and the majority of physicians still practice in solo, small partnerships, and small group practices paid largely on a fee-for-service basis. Therefore, the system is poorly designed to treat chronic illness - the major health challenge of the 21 st century.

To address the above challenge, the US in its current healthcare reform initiative is beginning to move away from the fee-for-service payment model to a capitation payment model based on a set dollar amount per 
enrolled subscriber either in total or per selected conditions; bundled payments comprising a single payment to both physicians and hospitals for specific procedures or conditions such as coronary artery bypass graft surgery and rewards or bonuses for achieving predetermined quality outcomes such as reducing preventable hospital readmissions. At the same time, the United States is experimenting with new organizational forms potentially able to respond to the new payment incentives. We discuss three such innovations - the Patient-Centered Medical Home (PCMH), the Accountable Care Organization (ACO) and the Population Health Management System (PHMS). These three are selected because of their potential for providing more cost effective disease prevention and management of patients with chronic illness. They are also selected because of their potential to build on and reinforce each other as a coherent, sustainable package of delivery system improvements. ${ }^{5}$ We review the evidence on the performance of each, the challenges involved, and finally identify the factors that might promote greater adoption and diffusion of successful models in both the United States and other countries.

\section{PATIENT-CENTERED MEDICAL HOME}

One response to the current lack of coordinated care for patients with chronic illness in the US is the Patient-Centered Medical Home. It provides patients with a primary care physician and a team that can deliver personalized, whole person, coordinated care across conditions, episodes of care, different providers and settings over time. It has been widely endorsed and supported by numerous professional organizations in the US and worldwide. ${ }^{6}$

The four key elements of the PCMH are its commitment to primary care; its emphasis on the patient as the center of all activities; its implementation of "new model" practice; and its association with increased payment incentives for providing more coordinated care. ${ }^{7}$ For a given population of patients, a PCMH provides continuous access to a primary care provider (which can include a nurse practitioner or physician assistant) and a care team guaranteeing first contact care. Patient-centered care recognizes the patient as the most important member of the care team. As such, the PCMH empowers patients and their families as active participants in the care process, partnering with them to understand and address their needs and preferences. "New Model" practice involves the adoption of electronic health records; implementation of the chronic care model including use of disease registries, guidelines, and patient self management 
support programs ${ }^{8-10}$; and active participation in continuous quality improvement initiatives. These "tools" enable the PCMH to track patient referrals, treatments, and information across providers. To undertake the expanded responsibility for actively coordinating care across the continuum of patient care, PCMHs would be paid a care coordination fee in addition to being eligible for additional income from participation in pay-forperformance programs and sharing in savings from providing care for less than established expenditure targets.

\section{The Evidence}

Early evidence from the evaluation of PCMHs suggests that the quality of care, patient satisfaction with care, care coordination itself, and access to care are better in the PCMH model than alternative practice models. There is also evidence that it has led to reductions in emergency room visits and hospitalizations. These results have been achieved at the same or lower cost than other modes of practice.

For example, using a prospective quasi-experimental design, investigators at Group Health Cooperative of Puget Sound in Seattle, Washington found a 29 percent reduction in emergency room visits and an 11 percent reduction in ambulatory care sensitive admissions for the PCMH model as compared to control sites. There were also significantly higher patient experience scores and less staff burnout. These improvements were accomplished with no increase in overall cost. The PCMH model is now being implemented in all 26 primary care clinics serving 380,000 patients within the Group Health Cooperative system. ${ }^{11}$

A second example comes from smaller practices in primarily rural North Carolina. The Community Care of North Carolina PCMH achieved a 40 percent decrease in hospitalizations for asthma and an 11 percent lower rate of emergency room visits. The total savings to the state's Medicaid and State Children Health Insurance Program (SCHIP) were between $\$ 135$ and $\$ 400$ million. The model now involves 1,300 community based practice sites and approximately 4,500 primary care clinicians throughout North Carolina. ${ }^{12}$ A similar program targeting children in Colorado resulted in median annual costs of $\$ 785$ per child for the PCMH model versus $\$ 1,000$ for a control group. The savings were achieved through reductions in emergency room visits and hospitalizations. ${ }^{13}$

A PCMH model in the Geisinger Health System, a private integrated delivery system, in western Pennsylvania using staff serving as "health navigators" who coordinate care for patients, resulted in a statistically significant 14 percent reduction in hospital admissions relative to the 
control group, and a 9 percent reduction in total cost over 24 months. The estimated \$3.7 million in net savings resulted in a return on investment of greater than 2 to $1 .{ }^{14}$

Finally, Intermountain Healthcare in Salt Lake City, Utah, a private integrated delivery system, has used the PCMH model to provide better care for seniors with chronic illnesses. To date, they have seen an absolute reduction of 3.4 percent in two-year mortality for high risk elderly patients relative to the control group. In addition, they have achieved a 10 percent relative reduction in hospitalizations and a net reduction in total costs of $\$ 640$ per patient per year and $\$ 1650$ among the highest risk patients. As a result, they are now implementing the PCMH model in 75 practices located in six different states. ${ }^{15}$

\section{The Challenge}

While there is evidence supporting the performance of the PCMH model once established, it is sobering to note that existing research suggests that few practices in the United States would currently qualify as PCMHs. Using an index measuring twenty elements of the PCMH, Rittenhouse et al. found an average of only seven elements present out of twenty in a 2008 study of relatively large medical groups. ${ }^{16}$ As shown in Figure 1, the percentage of medical home elements (the mean index value) implemented only begins to increase in practices consisting of at least 65 physicians and to fulfill half of the recommended elements in practices larger than 140 physicians. Thus, smaller practices, which constitute the majority of providers in both the United States and most other countries, will require considerable support and technical assistance to become fully functioning medical homes.

Research is also needed to identify a possibly smaller subset of the elements that are the most important for providing cost-effective care coordination. Whatever these key elements might be, current physician practices will need to make changes in structure - at the point of delivering care, in patient outreach, and in management. Examples of structural changes include establishing longer patient visit times, pairing physicians with physician assistants and/or nurse practitioners, and establishing email connectivity with patients. Point of care changes include active promotion of email and phone "visits," pre-visit chart reviews and visit planning, and use of "health maintenance reminders" embedded within the electronic medical record. Some patient outreach changes include medication follow-up and promotion of self-management workshops. Among the management changes to be considered are the use of rapid process improvement cycles, and salaried physician compensation. 


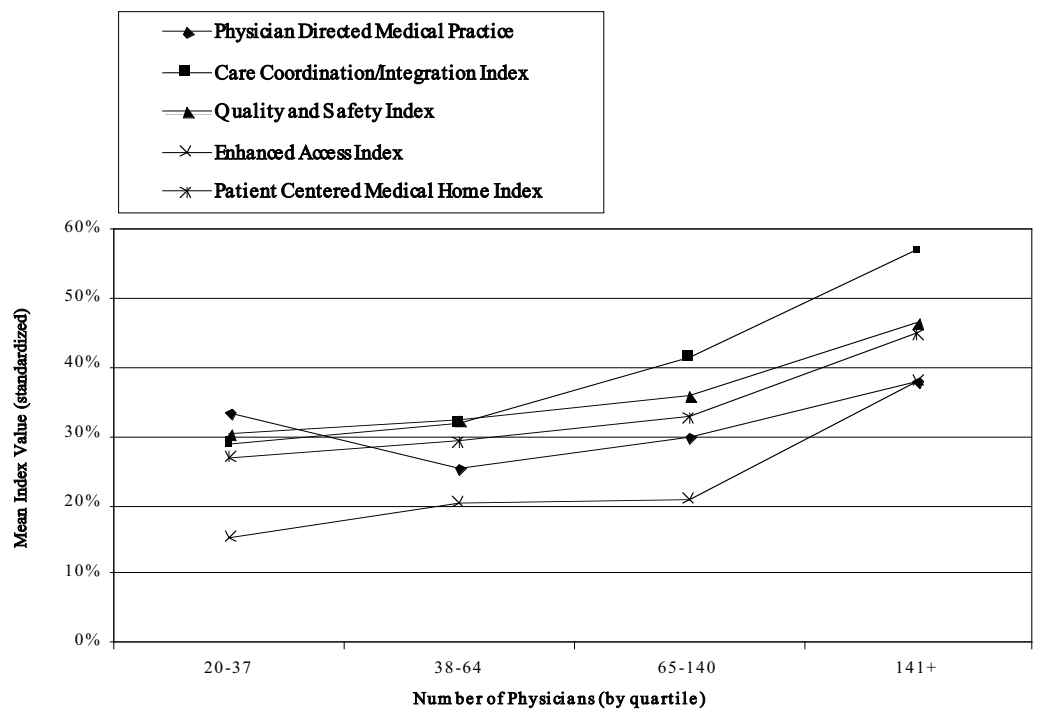

Fig. 1. Mean Index Value According to Size of Medical Group.

Source: Rittenhouse DR, Casalino LP, Gillies RR, Shortell SM, Lau B. Measuring the medical home infrastructure in large medical groups. Health Aff. 2008;27:1246-58.

Given the above, it is clear that the PCMH model cannot succeed as a stand-alone delivery system innovation. It must be coupled with a larger entity that can bring in other components of the delivery system, provide resources, create economies of scale, and implement accountability for performance. This entity is the Accountable Care Organization (ACO) discussed below.

\section{ACCOUNTABLE CARE ORGANIZATION}

Accountable Care Organizations are entities that accept responsibility for both the cost and quality of care provided to a defined population of patients and provide the data on performance. ${ }^{17-19}$ Along with the PCMH, ACOs are considered to be key elements of delivery system reform in the US, slowing the rate of increase in spending over time and providing more cost effective care to the population. ACOs typically include physician practices and at least one hospital, and could also include nursing homes, home health agencies, and other provider organizations. They provide the "umbrella" 
organization for PCMHs, specialty practices, hospitals, and other healthcare entities. They are particularly well suited for accepting capitation, partial capitation, specific episodes-of-care based, and bundled payments. In these payment mechanisms, the target levels of spending for the ACO would be established based on several years of prior data, adjusted for risk and overall inflation. Those ACOs that succeed in delivering care that meets or exceeds quality criteria for less than the expenditure target would be eligible to share in the savings. This creates economic incentives for hospitals, physicians, and other providers to work together to prevent unnecessary emergency room visits, intensive care hospitalizations, and repeat hospitalizations. Key components of ACOs are their local accountability for cost and quality, the ability to measure their performance, and the ability to create shared savings.

The ACO is not a uniform "one size fits all" concept. There are at least five different models of delivery that could serve as an ACO. These include the integrated or organized delivery system, multi-specialty group practices, physician hospital organizations, independent practice organizations, and "virtual" physician organisations. ${ }^{17,20}$

Examples of integrated or organized delivery systems in the United States include Kaiser Permanente, Group Health Cooperative of Puget Sound, Geisinger Health System in western Pennsylvania, the Henry Ford Health System in Detroit, Michigan, and the Intermountain Health System in Salt Lake City, Utah, among others. These systems not only own hospitals and other facilities but also have at least one salaried multi-specialty group practice and sponsor a health plan. They have extensive experience in providing care to defined populations of patients and have the breadth of services, resources, governance and leadership mechanisms to easily qualify as an ACO.

Examples of multi-specialty group practices include the Mayo Clinic in Minnesota, Florida and Arizona, the Billings Clinic in Montana, the Cleveland Clinic in Ohio, the Virginia Mason Clinic in Washington State, the Marshfield Clinic in Wisconsin, and others. Most of these practices own or have a strong affiliation with a hospital. They typically do not own a health plan but rather have contracts with multiple health plans in their areas. Most have a long history of physician leadership and have highly developed mechanisms for providing coordinated clinical care. Most of these practices would easily qualify as an ACO.

In the United States, physician-hospital organizations (PHOs) were formed in the 1990's largely as contracting mechanisms to negotiate with health plans. Most PHOs consist of a subset of the voluntary medical staffs 
of hospitals. As managed care pressures subsided, many of these organizations went out of existence, but it is estimated that nearly 1,000 PHOs exist to this day. Some, such as Advocate Health System in Chicago, Illinois and Middlesex Hospital in Connecticut, function similarly to the multi-specialty group practice in terms of their focus on reorganizing care delivery to achieve more cost-effective care coordination. While generally less well-suited than integrated delivery systems or multi-specialty practices, some PHOs could also structure themselves so as to become eligible to serve as an ACO.

Independent practice associations (IPAs) are comprised of individual physician practices that come together for purposes of contracting with health plans. They exhibit a great deal of variation in the extent to which they actively engage in practice redesign, quality improvement initiatives, and exchange of information to improve care delivery. While many remain networks of practices that exist for contracting purposes only, some such as Hill Physicians Group in Northern California and HealthCare Partners in Southern California function similarly to multi-specialty group practices. Thus, some IPAs could qualify as an ACO and others may move in that direction given strong financial incentives and technical assistance support.

Finally, independent small physician practices, mostly located in rural areas, can organize to become "virtual" physician organizations. This can be accomplished through the leadership of an individual physician in a rural area, a local medical foundation, a state Medicaid agency, or similar body that serves to provide the leadership and resources for helping small rural practices redesign their care, share information, and provide more cost-effective care. Examples include Community Care of North Carolina stimulated by the state Medicaid agency, Grand Junction Colorado, the North Dakota Rural Cooperative Network, and Humboldt County California. Such organizations could also qualify as ACOs and serve as a model for many other such practices throughout the United States.

Key to the success of the ACO model is the importance of measurement, the backbone for accountability. This involves specifying the types and level of measures used, the focus of measurement, and the focus of the provider. Currently, in the United States, measurement is most typically at the individual patient-provider level. In the ACO model, the level of measurement moves to the entire system or population of patients enrolled in or assigned to the ACO. By placing measurement at the population level, the hope is that fragmentation will be reduced and that care will be assessed at the population level across all patients over time. In regard to the type of measurement, the current emphasis is on process measures of care such as 
adherence to guidelines and recommended testing. In the ACO model, emphasis moves to looking at outcomes measures of care such as reduced disability days, functional health status scores and patient experience measures as well as overall efficiency of the care provided. The hope is that this will provide better data for patients to make choices about providers and better data for providers to make changes in their practices including increased accountability for resource use. The present focus of measurement is on the individual provider who is accountable for processes of care while in the ACO model, the measurement focus moves to overall care coordination and shared decision making. There is organizational support for managing and improving care and better patient engagement. Finally, the mainstream current provider focus in the United States is on discrete patient encounters, while in the ACO model, the provider focus shifts to the health of a given population of patients. The intended result is greater shared accountability for the continuum of care. ${ }^{21}$

Given this measurement focus and the implementation of new payment incentives such as capitation, partial capitation, and bundled payments, ACOs can potentially provide more cost effective care utilizing a number of mechanisms. These include expanded use of nurse practitioners and physician assistants; reducing waste by eliminating duplicate testing through a focus on internal process of improvement; providing full implementation of chronic care model disease management processes including patient self support; utilizing actionable, accurate, and timely data for both managing care and providing feedback to providers for continuous improvement; and making more informed choices about resource and facility capacity given a focus on a defined population of patients.

\section{The Evidence}

There is accumulating evidence that the more integrated forms of ACOs (integrated delivery systems and multi-specialty group practices) are providing superior care at the same or lower cost per capita than other delivery forms. ${ }^{22}$ Regarding cost of care, the number of hospital days, number of intensive care days, hospital costs, and physician costs have been shown to be less for Medicare patients in integrated delivery systems than for patients in other settings. ${ }^{23}$ Further, Medicare enrollees receiving care from multi-specialty or hospital-affiliated groups experienced lower overall costs than those receiving care from smaller groups or solo physicians. ${ }^{24}$ Also, the Mayo Clinic and Health Partners in Minnesota have 
achieved favorable return on investment from diabetic disease management programs. ${ }^{25,26}$

Evidence regarding the impact of ACOs on the quality of care provided is limited, in large part due to an inability to link data on provider organization characteristics to outcomes. However, the few studies that exist support this link. For example, in a study of 272 health plans, more integrated health plans (defined as either a group or a staff model) performed better than health plans with less integration on women's health screening, diabetes screening, heart disease screening, and immunization rates. ${ }^{27}$ California medical groups performed better than their IPA counterparts in terms of the percent of female enrollees who were current on mammograms and Pap smear screenings and the percent of patients with diabetes receiving eye exams. ${ }^{28}$ In Massachusetts, physician groups affiliated with healthcare networks scored better than non-affiliated groups on 8 out of 12 process of care measures. ${ }^{29}$

Research also indicates greater use of evidenced-based care management processes, health promotion programs, and prevention services among the more integrated ACOs. For example, a national study of medical groups and IPAs found that organized medical group practices were more likely to send reminders for preventive services than were the more loosely organized IPAs, ${ }^{30}$ and medical groups were four times more likely to offer health promotion programs such as smoking cessation, weight loss, stress management, and nutritional counseling than were IPAs. ${ }^{31}$ This study further showed that physician organizations that were affiliated with hospitals, health systems, or health plans used more care management processes, prevention services, and health promotion programs than did organizations that were physician owned. ${ }^{9}$

A cohort study of 369 large physician organizations showed that medical groups had a significantly greater increase from year 2000 to year 2006 in the number of care management processes used than IPAs. ${ }^{32}$ In a study of 119 California physician practices, integrated medical groups, defined as practices in which the physicians who practice are either salaried employees or partners, were more likely than IPAs, to send reminders for mammograms, pediatric well-child visits, and/or immunizations; collect data on patient satisfaction concerns (e.g., wait times); use diabetes disease management programs, and contact patients with diabetes about missed eye screenings. ${ }^{28}$ California community clinics as well as hospital-based clinics used more care management processes for asthma and diabetes in caring for predominantly Medicaid patients than did IPAs. ${ }^{33}$ 


\section{The Challenge}

A recent survey revealed that 70 percent of US hospital and medical leaders believe their organization could serve as an ACO within the next five years. ${ }^{34}$ However, as noted above, this will be a particular challenge for the more loosely organized IPAs and the small primarily rural physician practices. The ability of these groups to move towards qualifying as ACOs will require considerable technical assistance, pooled resources, and perhaps most importantly, local leadership. As a result, public policy in the US might best proceed by establishing different levels of eligibility criteria. The goal should be to strike a balance between the need for standards high enough to motivate desired behavior while recognizing at the same time the current largely fragmented small scale nature of physician practice in the United States. For example, a basic level I set of standards might include:

1. establishment of a legal entity with designated governance and management/leadership in place;

2. a minimum number of practices or "patient-centered medical homes", at least one hospital and a designated specialist referral panel for a defined population;

3. a sufficient volume of patients that might vary depending on the overall population of the area; and

4. the ability to provide basic laboratory and medication data for all patients.

An intermediate or level II set of criteria might include the previous elements plus:

1. use of disease registries, guidelines, and patient reminder systems; and

2. increased electronic health record functionality.

The advanced level III might include the previous items plus:

1. implementation of the full portfolio of chronic care model processes including strong patient self management support systems;

2. use of nurse care managers for severely chronically ill patients;

3. a medication management system;

4. ongoing participation in formally organized quality improvement programs; and

5. fully functional electronic health records. The degree of financial risk and rewards undertaken would vary accordingly, being lowest for level I ACOs and highest for level III.

Together, the PCMH and the ACO can provide the portfolio of primary care coordination capabilities, specialist and hospital capacity, and the size 
and scale to respond to payment incentives and performance measurement requirements associated with explicit accountability for both the quality and cost of care. They can fulfill the six attributes of high performing health systems including information continuity, care coordination for transitions in care, system accountability, peer review and teamwork, continuous innovation, and easy access to appropriate care..$^{35}$

However, from a population-based public health perspective, they fall "one step short" in that they fail to address the underlying cross-sector physical and social determinants of health necessary for preventing chronic illness. For this to occur, a third innovation is needed - what we call the Population Health Management System (PHMS).

\section{THE POPULATION HEALTH MANAGEMENT SYSTEM}

To improve the health of populations and reduce the per capita cost of healthcare, all nations will need to go beyond improvements in the performance of their healthcare delivery systems to embrace the broader determinants of health. This will involve the development of cross-sector organizations or networks that collectively take responsibility for population health. Two US innovations in this regard are the "Health Outcomes Trust" 36 and what we have previously called the Community Healthcare Management System. ${ }^{37}$ Since these share the same essential ideas, we merge them into one concept and call it the Population Health Management System.

As shown in Figure 2, the PHMS draws together all of the community health-building assets (the education sector, transportation sector, etc.) to enhance population health with the goal of keeping as many people as possible "chronically well". Payment is made to the PHMS based on its achievement of predetermined population health measures.

The organizational form of the PHMS can vary depending on local circumstances. However, the key is that it would be publicly accountable to local, state, and national governmental bodies. The core responsibility of the PHMS entity is to:

1. assess the health status of the community and develop a resulting set of priorities for addressing its needs;

2. work with the various cross-sector component organizations to develop strategies and implement action plans to achieve the agreed upon goals; and

3. assure accountability for performance against the goals and aims. 


\begin{tabular}{|c|c|}
\hline $\begin{array}{l}\text { Payment Based on } \\
\text { Achieving }\end{array}$ & $\begin{array}{l}\text { Selected Population Health Measures e.g. Infant } \\
\text { Mortality, Percent Children Overweight / Obese, }\end{array}$ \\
\hline Measures & School Loss Days, Quality Adjusted Life Years \\
\hline
\end{tabular}
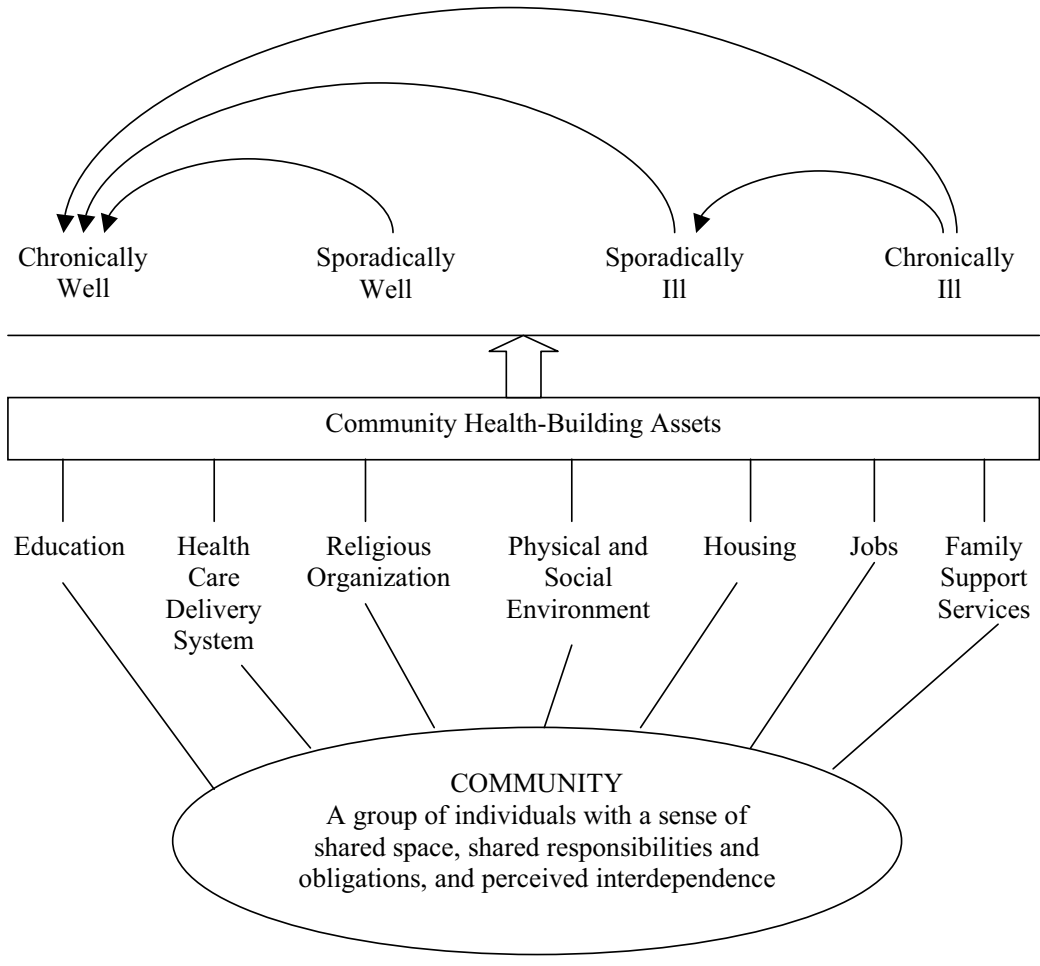

Fig. 2. Population Health Management System.

Source: Adapted from Shortell SM, Gillies RR, Anderson DA, Erickson KM, Mitchell JB. Remaking healthcare in America: the evolution of organized delivery systems, $2^{\text {nd }}$ ed, San Francisco: Jossey-Bass, July 2000, p. 264.

PCMHs and ACOs can play an important role in the PHMS by coordinating the downstream care delivery work with the upstream community health building work of other organizations such as the health departments, community-based health organizations, schools, and the business community. 
For example, Group Health of Puget Sound and Kaiser Permanente have developed a Population Health Management Model based on five stages of health including presymptomatic conditions, symptomatic conditions, acute conditions, chronic conditions, and end-of-life care. For each stage, they have identified relevant community health building activities and the associated organizations to address them.

In the presymptomatic stage of healthy individuals, the primary activities involve health status assessment and potential demand management, disease prevention, and health promotion. Relevant bodies for health status assessment include the health department, hospitals and health systems, and community based organizations. Relevant organizations for demand management, disease prevention, and health promotion include the business community in generating jobs, housing, education, city and regional planning, family support services, and law enforcement, in addition to healthcare providers, health departments, hospitals and health systems.

In the symptomatic stage, self care management is the dominant focus. Here, the relevant partnerships involve the internet, family support services, and again the employment, housing, education, and environmental sectors, as well as faith-based community organizations, health professionals, hospitals and health systems. The acute and chronic stages and end-of-life stages involve professional disease management with an emphasis on physicians and other health professionals, hospital and health systems, long-term care and rehabilitation facilities, family support and religious organizations, housing, environment, and once again the internet.

The greatest contribution of population health is achieved by keeping people in the presymptomatic state. In the population health management system, PCMHs and ACOs will play key facilitating and supportive roles in working with organizations in the various sectors to prevent illness and disability.

\section{The Evidence}

It is difficult to assess the impact of such partnerships given the long time period usually needed to make such assessments and the many confounding factors involved. Nonetheless, there is some evidence that community-wide population-based partnerships may have been associated with significant reductions in such areas as lead poisoning, teenage pregnancy, infant mortality, and motor vehicle accidents. ${ }^{38}$ Assessment of the cost and costeffectiveness of such innovations is an area of ongoing research. ${ }^{39}$

While unlikely to result in short run cost savings, there is renewed emphasis on and understanding of the importance of disease prevention 
and health promotion initiatives in slowing the rate of increase in cost over time and contributing to a greater number of years of quality of life and productivity in the US. As a result, the US goals for health reflected in the new Healthy People 2020 objectives have placed greater emphasis on the underlying cross-sector physical and social determinants of health. The key to realizing these goals will be to align the financial and payment incentives to encompass a wider umbrella of cross-sector organizations than PCMHs and ACOs, so as to induce the desired behavior.

\section{The Challenge}

Creating a cross-sector organizational entity that can serve as the PHMS is a major challenge. Each organization and each sector has its own goals and objectives to focus on. What is needed is for each entity to understand that it can only accomplish its own objectives in collaboration with the other organizations. For example, for schools to achieve their educational objectives, their children must be healthy, present at school, and able to learn. For the transportation agencies to receive government funding for roads, they must be able to meet traffic safety criteria. For the housing department to issue construction permits to developers, the developers must meet air, water, and, traffic safety standards and provide open spaces for physical activity. In brief, high levels of work interdependence must be created among the different sectors. This, in turn, must be reinforced by strong financial incentives for collaborative action to counter the natural tendency for partner organizations to pursue their own agendas. ${ }^{40}$ Sophisticated leadership and management is also needed to deal with the coordination costs involved and the challenges of blending cultures from different organizations. These challenges are particularly acute in the US with the emphasis on autonomy and individualism as opposed to the greater emphasis on social solidarity and social responsibility for health found in Canada and much of Europe.

Despite these challenges, there are examples of such partnerships developing that could form the basis for PHMS. One example is the 25 community care networks (CCNs) developed in the 1990s through the sponsorship by the American Hospital Association/Hospital Research and Educational Trust. ${ }^{41}$ Another example is the Centers for Disease Control (CDC) Healthy Communities Initiatives that brings together a diverse group of institutions targeted to preventing chronic disease involving obesity, asthma and diabetes. ${ }^{42}$ Participation in such partnerships appears to be growing. ${ }^{40}$ 


\section{EXAMPLES OUTSIDE OF THE UNITED STATES}

There are many innovations in Europe, Australia, Canada, New Zealand, and other countries similar to those in the US. Most of these efforts focus on how to improve primary care and its capacities to better prevent and manage chronic illness. The evidence suggests that implementation of the chronic care model is associated with improved outcomes, particularly in regard to delivery system design and patient self-management support. ${ }^{43-45}$ Given the importance of delivery system design, many of these countries have formed organizations similar to the PCMHs and ACOs emerging in the US. For example, many of England's Primary Care Trusts (PCTs) are now participating in integrated care pilots. ${ }^{46}$ These pilots are primarily designed to strengthen partnerships between the Trust and local community and social welfare agencies to improve the overall coordination of care. These are significant because the Trusts also have pre-determined budgets like that planned for the US based ACOs. Similar organizations have emerged in New Zealand. Called primary health organizations (PHOs), they are designed to coordinate care and engage communities but without budgetary authority. Over 95 percent of New Zealanders are enrolled through their general practitioners. ${ }^{47}$ Specialist care is incorporated through Integrated District Health Boards which assume responsibility for the full continuum of care.

Canada has developed family health networks (FHNs) similar to the US based PCMHs with the emphasis on multidisciplinary teams, chronic disease management, health promotion and disease prevention. ${ }^{48}$ Scotland is attempting to link its Managed Clinical Networks (MCNs) to its Community Health Partnerships (CHPs) to provide better coordination of primary and secondary care and encourage a greater population-based focus. ${ }^{49}$ In Australia, there is increasing focus on multidisciplinary primary care teams and investment in general practice (GP) super clinics with greater emphasis on disease prevention and health promotion. ${ }^{50}$

The advantage that Europe, Canada, Australia, New Zealand and many other countries have over the US is a stronger base of primary care upon which to build the efforts on earlier disease prevention and better care coordination for the chronically ill. The extent to which the US innovations in healthcare delivery can be brought to scale and diffused throughout the country will depend on a combination of strong financial incentives, enhanced primary care capability, continuing advances in performance measurement and accountability, and local leadership. 


\section{SUGGESTIONS FOR FURTHER ADOPTION AND DIFFUSION}

As the world becomes more of a global neighborhood, there is more rapid spread of information and knowledge among all nations and in all sectors, including health, and there is much that countries can learn from each other. The key to successful learning will be each country's ability to recognize the role played by its political system and its associated culture, structural barriers, size and resources, incentive alignment, and professional leadership. Given space constraints, these issues are only briefly touched upon here but deserve further treatment.

Each country's health system is a reflection of its political/governmental systems and core values or culture. Canada and Europe, for example, exhibit much greater commitment to social solidarity values than the US. One consequence of this is the much lower incomes of physicians in these countries than in the US. Furthermore, in most other countries, government exerts greater direct control over healthcare policy and expenditures through setting global budgets and/or tough negotiations on fee schedules with providers than is true in the US. One result of this is that once accepted as policy in these countries, such innovations can be implemented and spread more rapidly throughout the healthcare system than is the case in the decentralized US system. For example, when England decided to convert their primary care practices into budget holding primary care trusts, this decision was made for the entire country and implemented throughout. In contrast, the US is "pilot testing" PCMHs and ACOs through demonstrations that may last several years. Even then, practices will most likely be given the opportunity to voluntarily join such organizations.

Institutional structural barriers also place constraints on the spread of organizational innovations. For example, the longstanding separation of the hospital-based specialists from the community-based primary care physicians in the United Kingdom has hampered efforts at coordination for the chronically ill. Today, very few of the integrated care pilots have involved the hospital sector. ${ }^{45}$ Similar structural barriers exist in most other countries. For example, the US has a longstanding history of strained relationships between hospitals and physicians that have been only occasionally mitigated by effective medical staff organizations and related structures. ${ }^{51}$

Size and resources also exert important influences on the adoption and spread of innovations such as the PCMHs, ACOs, and PHMS. In many countries, including the United States, in particular, physician practices are simply too small to meet the coordination demands for caring for chronically ill patients. To be able to respond to new payment incentives, providers 
need to develop new capabilities in using electronic medical records, forming healthcare teams, using nurse practitioners, physician assistants, pharmacists, dietitians, and social workers, and redesigning their practices. As previously noted, this will require forming partnerships and alliances with governmental or private sector organizations in order to provide the necessary technical assistance and related resource support.

All countries are challenged to align the financial and related incentives to induce desired behavior. For example, the United Kingdom recently provided incentives to primary care physicians for improving access in order to reduce waiting lists and for implementing various elements of the preventive and chronic care model. Better than expected results were achieved, resulting in an unexpected higher amount of additional income to providers, placing strain on the overall United Kingdom budget. ${ }^{52}$ In the US, payment is changing from fee-for-service to the creation of more shared incentives for hospitals and physicians to collaborate in coordinating care and to be paid for keeping patients healthy. As noted, one example is the use of a single payment to both hospitals and physicians for all of the care associated with such procedures as coronary artery bypass graft surgery, total hip and total knee replacements - an approach called bundled payments. The payment would be risk-adjusted for patient severity of illness. Hospitals and physicians would share in any savings resulting from providing care that met quality standards while staying below cost targets. A related approach is to make a single payment for an episode-of-illness such as for diabetes or asthma care for a defined period of time. This approach can also be extended to an entire population of patients in which a budget is set, based on the population's health status and risk profile, expressed as a defined dollar figure per person or what is called capitation. These payment models and additional incentives for achieving cost and quality goals will be critical for motivating desired changes in practice organizations. What is needed is the coevolution of payment and new delivery organization. This will be a greater challenge for the United States than most other countries due to the heterogeneity of US physician practices.

Perhaps most important in spreading initiatives such as the PCMHs, the ACOs, and the PHMS concepts is the quality of leadership at all levels of a country's health system. All of the various stakeholders have interests in preserving the status quo. Strong persuasion, negotiation, and partnershipbuilding skills are particularly needed in countries such as the US where the medical profession enjoys relatively greater autonomy. People need to believe in and ultimately see the advantages of new forms of organizations 
to manage the new fiscal realities. The development of cross-sector (health, education, transportation, housing, etc.) collaborations to form a PHMS to improve the public's health through better prevention and management of chronic illness will place a premium on leadership skills.

\section{CONCLUSION}

Throughout the world, the coming decades will further integrate public health and healthcare delivery to reduce the growing chronic illness burden of disease on economic growth, quality of life, and global security. This is the New Public Health. The extent to which people can enjoy a high quality of life at every stage of the lifespan will require continued experimentation and innovations such as those represented by PCHMs, ACOs, and PHMSs and associated changes in how they are paid. Ongoing evaluation of their impact on improving personal and population health will be needed. Innovative leadership within both government and the private sector will be required to promote such changes in all countries' healthcare delivery systems.

\section{Acknowledgements}

We thank Joanna Yu for her assistance in the preparation of this manuscript.

Contributors: Stephen Shortell and Robin Gillies conceived this paper and made the first drafts; Frances Wu made substantial revisions and developed subsequent drafts.

Conflicts of interest: None declared.

\section{REFERENCES}

1. Daar AS, Singer PA, Persad DL, Pramming SK, Matthews DR, Beaglehole R. et al. Grand challenges in chronic non-communicable diseases. Nature. 2007;450:494-6.

2. World Health Organization. Preventing chronic diseases: a vital investment. Geneva: World Health Organization; 2005.

3. American College of Physicians: Health and Public Policy Committee. Achieving a high performance health care system with universal access: what the United States can learn from other countries. Ann Intern Med.2008;148: 55-75.

4. U.S. Department of Health and Human Services. The power of prevention: reducing the health and economic burden of chronic disease. Atlanta: Centers for Disease Control and Prevention, National Center for Chronic Disease Prevention and Health Promotion; 2003. 
5. Rittenhouse DR, Shortell SM, Fisher ES. Primary care and accountable care two essential elements of delivery system reform. N Engl J Med. 2009; 361:2301-3.

6. Patient-Centered Primary Care Collaborative. Web site: URL: http://www. pcpcc.net/index.php. (Accessed 26 February, 2010).

7. Rittenhouse DR, Shortell SM. The patient-centered medical home: will it stand the test of health reform? JAMA. 2009;30:2038-40.

8. Wagner EH, Austin BT, Davis C, Hindmarsh M, Schaefer RJ, Bonomi A. Improving chronic illness: translating evidence into action. Health Aff. 2001;20:64-78.

9. Casalino LP, Gillies RR, Shortell SM, Schmittdiel J, Bodenheimer T, Robinson $\mathrm{JC}$, et al. External incentives, information technology, and organized processes to improve health care quality for patients with chronic diseases. JAMA. 2003;289:434-41.

10. Friedberg MW, Coltin KL, Safran DG, Dresser M, Zaslavsky AM, Schneider EC. Associations between structural capabilities of primary care practices and performance on selected quality measures. Ann Intern Med. 2009; 151:456-63.

11. Reid RJ, Fishman PA, Yu O, Ross TR, Tufano JT, Soman MP, et al. Patientcentered medical home demonstration: a prospective quasi-experiment, before and after evaluation. Am J Manag Care. 2009;15:71-87.

12. Steiner BD, Denham AC, Ashkin E, Newton WP, Wroth T, Dobson LA. Community care of North Carolina: improving care through community health networks. Ann Fam Med. 2008;6:361-7.

13. Grumbach K, Bodenheimer T, Grundy P. The outcomes of implementing patient-centered medical home interventions: a review of the evidence on quality, access and costs from recent prospective evaluation studies. Washington (DC): Patient-Centered Primary Care Collaborative; August 2009.

14. Graf TR. Geisinger Clinic Proven Health Navigator Model ICSI update, May 2009. Danville (PA): Geisinger:2009.

15. Dorr DA, Wilcox AB, Brunker CP, Burdon RE, Donnelly SM. The effect of technology-supported, multidisease care management on the mortality and hospitalization of seniors. J Am Geriatr Soc. 2008;56:2195-202.

16. Rittenhouse DR, Casalino LP, Gillies RR, Shortell SM, Lau B. Measuring the medical home infrastructure in large medical groups. Health Aff. 2008; 27:1246-58.

17. Shortell SM, Casalino LP. Health care reform requires accountable care systems. JAMA. 2008;300:95-7.

18. Fisher ES. Building a medical neighborhood for the medical home. N Engl J Med. 2008;359:1202-5.

19. McKethan A, McClellan M. Moving from volume-driven medicine toward accountable care. Health Aff Blog. 2009; August 20. 
20. Shortell SM, Casalino LP, Fisher ES. Achieving the vision: structural change. In: Crosson FJ, Tollen LA, editors. Partners in health: how physicians and hospitals can be accountable together. San Francisco: Jossey-Bass; 2010.

21. Engelberg Center for Health Care Reform at Brookings. Department of Institute for Health Policy and Clinical Practice. Bending the cost curve: effective steps to address long-term health care spending growth. Washington (DC): The Brookings Institution; 2009.

22. Tollen LA. Physician organization in relation to quality and efficiency of care: a synthesis of recent literature. New York NY: The Commonwealth Fund; 2008.

23. Sterns JB. Quality, efficiency, and organizational structure. J Health Care Finance. 2007;34:100-7.

24. Park E. Informing the debate about curbing Medicare Advantage overpayments. Washington DC: Center on Budget and Priorities; 2007.

25. Eggleston KN, Shah ND, Smith SA, Wagie AE, Williams AR, Grossman JH, et al. The net value of health care for patients with type 2 diabetes, 1997 to 2005. Ann Intern Med. 2009;151:386-93.

26. Beaulieu N, Cutler DM, Ho K, Isham G, Lindquist T, Nelson A, et al. The business case for diabetes disease management for managed care organizations. Berkeley CA: Berkeley Electronic Press; Forum for Health Economics and Policy. 2006;9(1).

27. Gillies RR, Chenok KE, Shortell SM, Pawlson G, Wimbush JJ. The impact of health plan delivery system organization on clinical quality and patient satisfaction. Health Serv Res. 2006;41:1181-99.

28. Mehrotra A, Epstein AM, Rosenthal MB. Do integrated medical groups provide higher-quality medical care than individual practice associations? Ann Intern Med. 2006;145:826-33.

29. Friedberg MW, Safran DG, Coltin KL, Dresser M, Schneider EC. Readiness for the patient-centered medical home: structural capabilities of Massachusetts primary care practices. J Gen Intern Med. 2009;24:162-9.

30. Schmittdiel J, McMenamin SB, Halpin HA, Gillies RR, Bodenheimer T, Shortell SM, et al. The use of patient and physician reminders for preventive services: results from a National Study of Physician Organizations. Prev Med. 2004;39:1000-6.

31. McMenamin SB, Schmittdiel J, Halpin HA, Gillies R, Rundall TG, Shortell SM. Health promotion in physician organizations: results from a national study. Am J Prev Med. 2004;26:259-64.

32. Shortell SM, Gillies R, Siddique J, Casalino LP, Rittenhouse DR, Robinson JC et al. Improving chronic illness care: a longitudinal cohort analysis of large physician organizations. Med Care. 2009;47:932-9.

33. Rittenhouse DR, Robinson JC. Improving quality in Medicaid: the use of care management processes for chronic illness and preventive care. Med Care. 2006;44:47-54. 
34. Shortell SM. Accountable Care Organizations. In: The Society for Healthcare Strategy and Market Development (editor). Futurescan 2010: health care trends and implications 2010-2015. Chicago (IL): American Hospital Association; 2010.

35. McCarthy D, Mueller K. Organizing for higher performance: case studies of organized delivery systems. New York: The Commonwealth Fund; 2009.

36. Kinding DA. Purchasing population health: paying for results. Ann Arbor (MI): University of Michigan Press; 1997.

37. Shortell SM, Gillies RR, Anderson DA, Erickson KM, Mitchell JB. Remaking health care in America: the evolution of organized delivery systems. 2nd ed. San Francisco: Jossey-Bass; 2000.

38. Roush S, Birkhead G, Koo D, Cobb A, Fleming D. Mandatory reporting of diseases and conditions by health care professionals and laboratories. JAMA 1999;282:164-70.

39. Cohen JT, Neumann PJ, \& Weinstein MC. Does preventive care save money? Health economics and the presidential candidates. N Engl J Med. 2008; 358:661-3.

40. Mays GP. Improving public health system performance of multi-organizational partnerships: recent advances and future prospects. 2009 Working Paper.

41. Conrad DA, Cave SH, Lucas M, Harville J, Shortell SM, Bazzoli GJ. et al. Community care networks: linking vision to outcomes for community health improvement. Med Care Res Rev. 2003;60(4 Suppl):95S-129S.

42. Hawkins C, O'Garro MA, Wimsett K. Engaging employers to develop healthy workplaces: the WorkWell initiative of Steps to a Healthier Washington in Thurston County. Prev Chronic Dis. 2009;6:A61.

43. Tsai AC, Morton SC, Mangione CM, Keeler EB. A meta-analysis of interventions to improve care for chronic illnesses. Am J Manag Care. 2005;11:478-88.

44. Zwar N, Harris M, Griffiths R, Roland M, Dennis S, Powell Davies G, et al. A systematic review of chronic disease management. Canberra, Australia: Australian Primary Care Health Research Institute, The University of New South Wales School of Public Health and Community Medicine; 2006.

45. Ham C. The ten characteristics of the high-performing chronic care system. Health Econ Policy Law. 2010;5:71-90.

46. Smith J, Goodwin N. Towards managed primary care: the role and experience of primary care organisations. Aldershot (UK): Ashgate Publishing Limited. 2006.

47. Gauld R, Mays N. Are New Zealand's new primary health organisations fit for purpose? BMJ. 2006;333:1216-8.

48. Meuser J, Bean T, Goldman J, Reeves S. Family health teams: a new Canadian interprofessional initiative. J Interprof Care. 2006;20:436-8.

49. Clark JD. Managed clinical network: what are they and how do they work? Dent Update. 2007;34(7):443-4, 447-8, 450.

50. Kidd MR. What impact will the change of federal government have on the Australian general practice? Med J Aust. 2008;189:62-5. 
51. Burns LR, Muller RW. Hospital-physician collaboration: landscape of economic integration and impact on clinical integration. Milbank Q. 2008;86:375-434.

52. Campbell S, Reeves D, Kontopantelis E, Middleton E, Sibbald B, Roland M. Quality of primary care in England with the introduction of pay for performance. N Engl J Med. 2007;357:181-90. 